\title{
Mobile-based Interventions in Nursing Education among Undergraduate Nursing Students: An Analysis
}

\author{
Airul Azizan Zainudin, Hazwani Mohd Mohadis, Norfadzilah Ahmad
}

\begin{abstract}
There is an enormous pressure for nursing education institution to become more dynamic to engage in fast-growing educational technology into the curriculum. This study discussed the literature on the implementation of mobile learning intervention in undergraduate nursing education mainly targeting learning outcomes and understanding the features and elements of mobile technology that lead to the success and failure of the interventions. Four main online databases searched; there were Ovid, Scopus, CINAHL and ProQuest. Citation tracking and scrutiny of reference lists were also undertaken in the search for additional papers. We included twelve papers reporting on mobile-based intervention with nursing learning activities. Seven out of twelve reported the employment of quasi-experimental pre-posttest, meanwhile four used randomized-controlled trial, and one experimental pre-posttest. Eight studies were from South Korea, two were from Taiwan, and one was from Finland and Brazil. Four implemented video-based, while the other three were virtual learning object, auditory-based content and communication-based intervention. Among the advantages of mobile technology addressed were easy access and promote learning feedback, which has subsequently resulted in improved retention of knowledge, skill performance, satisfaction and self-efficacy. Meanwhile, the disadvantages were lack of user satisfaction among video-based intervention studies and low skill practice score in auditory- and social network- based intervention studies. In summary, there were no single study claimed that their study as effective for clinical skill learning since the outcomes were unclear, but there is still room for improvement with better intervention design.
\end{abstract}

Index Terms: Education, Mobile Applications, Nursing, Review, Smartphone

\section{INTRODUCTION}

Nursing education is one of the programs that offer mass hands-on practical in their curriculum, now overtaking traditional conservative teaching technique by evolving through contemporary academic resources online [1]. In response to receiving many challenges in particular from clinical learning environment [2], self-awareness and

Revised Manuscript Received on July 12, 2019.

Airul Azizan Zainudin, Department of Professional Nursing Studies, Kulliyyah of Nursing, IIUM, Kuantan, Malaysia.

Hazwani Mohd Mohadis, Department of Information System, Kulliyyah of ICT, IIUM, Gombak, Malaysia.

Norfadzilah Ahmad, Department of Professional Nursing Studies, Kulliyyah of Nursing, IIUM, Kuantan, Malaysia. self-evaluation are new teaching strategies that research has shown to be effective in improving learning outcomes [3]. As a result of a breakthrough in information technology and communication in parallel with advancement in teaching methodologies, a change towards outcome-based learning has sparked a shift towards independent and active learning strategies. Hence, there is an enormous pressure for nursing education institution to become more dynamic to engage this fast-growing educational technology into their curriculum. With the growing reliance on mobile devices among younger generation especially Generation Y, where defined as a unique group of the population possessing "the most technically literate, educated, and ethnically diverse" [4], we must take this opportunity to associate these qualities into nursing educational interventions. To enhance the knowledge and practice of nursing education, mobile-based interventions propelled by today's technology advancement such as wireless internet and mobile technology can be manipulated [5]. Further, as more works of literature suggest an increment of effectiveness on mobile-enhanced learning in preventing resource limitation and subsequently improving opportunity for the student to learn, it is pivotal for us to explore the potential of mobile technology to encourage the acquisition of knowledge and practice of clinical skill among undergraduate nursing students.

Previous studies have discussed in-depth the types of concerns that become the central problems surroundings the use of mobile devices in nursing education that cause the adoption of the mobile learning to become difficult [6]-[11]. However, as the advantages have been promising and recognized to be beneficial as well, it has led to further exploration of its potential usages [6]-[14]. Hay et al. [13] and Mosa, Yoo and Sheets [15] for example has reported that the number of health professionals utilizing mobile technology in a clinical setting has increased, which further signalling the potential of acceptance and subsequently the use of smartphone technology as a platform for effective learning intervention in clinical learning area to a larger scale.

Self-directed learning is among the core elements of mobile learning environments [16], [17]. Mobile learning environments enable students to control the pace of their learning as well as acquiring advanced cognitive behaviours 
[16], [18]. Recently published systematic review studies, of mobile technology that lead to the success and failure of

\begin{tabular}{|c|c|c|c|}
\hline $\begin{array}{l}\text { Study, } \\
\text { Location }\end{array}$ & $\begin{array}{l}\text { Mobile } \\
\text { technology }\end{array}$ & Setting & Aim \\
\hline $\begin{array}{l}{[20]} \\
\text { Brazil }\end{array}$ & $\begin{array}{l}\text { Mobile-based } \\
\text { virtual learning } \\
\text { object (VLO) }\end{array}$ & Classroom & $\begin{array}{l}\text { To assess the results in learning among undergraduate nursing students } \\
\text { about assessment of acute pain in adults and newborns, before and after an } \\
\text { online educational intervention. }\end{array}$ \\
\hline $\begin{array}{l}{[21]} \\
\text { South } \\
\text { Korea }\end{array}$ & $\begin{array}{l}\text { Mobile-based } \\
\text { video }\end{array}$ & $\begin{array}{l}\text { Skill } \\
\text { laboratory }\end{array}$ & $\begin{array}{l}\text { To evaluate the effects of using a mobile-based video clip as an adjunct to } \\
\text { the clinical teaching of urinary catheterization in undergraduate nursing } \\
\text { students. }\end{array}$ \\
\hline $\begin{array}{l}{[22]} \\
\text { South } \\
\text { Korea }\end{array}$ & $\begin{array}{l}\text { Smartphone } \\
\text { app }\end{array}$ & $\begin{array}{l}\text { Skill } \\
\text { laboratory }\end{array}$ & $\begin{array}{l}\text { To evaluate the effectiveness of smartphone application by measuring } \\
\text { nursing students' knowledge, skills, and confidence in simulated } \\
\text { performance when providing care for infant airway obstruction. }\end{array}$ \\
\hline $\begin{array}{l}{[23]} \\
\text { Taiwan }\end{array}$ & $\begin{array}{l}\text { Mobile } \\
\text { assistant } \\
\text { learning system }\end{array}$ & Classroom & $\begin{array}{l}\text { To evaluate the score of learning performance on mobile assistant learning } \\
\text { during Problem Based Learning (PBL) activities. }\end{array}$ \\
\hline $\begin{array}{l}{[24]} \\
\text { South } \\
\text { Korea }\end{array}$ & $\begin{array}{l}\text { Mobile } \\
\text { applications }\end{array}$ & $\begin{array}{l}\text { Skill } \\
\text { laboratory }\end{array}$ & $\begin{array}{l}\text { To understand the effectiveness of mobile applications by comparing the } \\
\text { effectiveness of a high-fidelity human patient simulator to that of a mobile } \\
\text { application on student learning }\end{array}$ \\
\hline $\begin{array}{l}{[25]} \\
\text { South } \\
\text { Korea }\end{array}$ & $\begin{array}{l}\text { Mobile } \\
\text { application }\end{array}$ & $\begin{array}{l}\text { Class, skill } \\
\text { laboratory }\end{array}$ & $\begin{array}{l}\text { To determine the effect of mobile-based discussion versus computer-based } \\
\text { discussion on self- directed learning readiness, academic motivation, } \\
\text { learner-interface interaction, and flow state }\end{array}$ \\
\hline $\begin{array}{l}{[26]} \\
\text { South } \\
\text { Korea }\end{array}$ & $\begin{array}{l}\text { Mobile } \\
\text { application }\end{array}$ & Clinical site & $\begin{array}{l}\text { To examine the effect of an experiment that introduced a mobile AEMR } \\
\text { application for undergraduate nursing students in their practicum }\end{array}$ \\
\hline $\begin{array}{l}{[27]} \\
\text { South } \\
\text { Korea }\end{array}$ & $\begin{array}{l}\text { Smartphone } \\
\text { video } \\
\text { recordings }\end{array}$ & $\begin{array}{l}\text { Skill } \\
\text { laboratory }\end{array}$ & $\begin{array}{l}\text { To investigate the effects of learning with smartphone video recordings in } \\
\text { general 'intramuscular injection' practice for sophomore nursing } \\
\text { students. }\end{array}$ \\
\hline $\begin{array}{l}{[28]} \\
\text { South } \\
\text { Korea }\end{array}$ & $\begin{array}{l}\text { Smartphone } \\
\text { application }\end{array}$ & Classroom & $\begin{array}{l}\text { To describe the effectiveness of a smartphone-based dosage calculation } \\
\text { training application learning achievement, metacognition, and flow based } \\
\text { on prior knowledge among nursing students }\end{array}$ \\
\hline $\begin{array}{l}{[29]} \\
\text { South } \\
\text { Korea }\end{array}$ & Social network & $\begin{array}{l}\text { Skill } \\
\text { laboratory }\end{array}$ & $\begin{array}{l}\text { To investigate the effect of learning core fundamental nursing skills with } \\
\text { Social Network Service (SNS) on the learning satisfaction, self- efficacy, } \\
\text { and core fundamental nursing skills (tracheostomy care) of nursing } \\
\text { students. }\end{array}$ \\
\hline $\begin{array}{l}{[30]} \\
\text { Taiwan }\end{array}$ & $\begin{array}{l}\text { Smartphone- } \\
\text { video }\end{array}$ & $\begin{array}{l}\text { Skill } \\
\text { laboratory }\end{array}$ & $\begin{array}{l}\text { To study the effects of skill demonstration video delivered by smartphone } \\
\text { on facilitating nursing students' nursing skill competency and confidence }\end{array}$ \\
\hline $\begin{array}{l}{[31]} \\
\text { Finland }\end{array}$ & $\begin{array}{l}\text { Mobile } \\
\text { applications }\end{array}$ & Clinical site & $\begin{array}{l}\text { To evaluate the effectiveness of the mobile cooperation intervention in } \\
\text { improving the competence and self-efficacy of students and the quality of } \\
\text { the clinical learning environment. }\end{array}$ \\
\hline
\end{tabular}

critically appraise the literature on the implementation of mobile technology in undergraduate nursing education, used to summarise without highlighting the features and elements Table I Study location, mobile technology utilized, setting and aims

the effectiveness of the mobile learning intervention, features and elements of the mobile technology that lead to the success and failure of the interventions.

Four primary online databases searched; there were Ovid, Scopus, CINAHL and ProQuest. A combination of various keywords for 'nursing students' and 'mobile technology' was used. Citation tracking and scrutiny of reference lists were also undertaken in the search for additional papers. The literature was taken which published between $1^{\text {st }}$ January 2013 until $31^{\text {st }}$ December 2018 to ensure the broad range of mobile technology usage. Only literatures that are written in English language were considered to be taken in this study because it is comprehensible by the researcher and the particularly on its effect on learning outcomes as well as the intervention [19]. Thus, a review study is needed to identify

participants. Further, only studies that conducted the actual observation or experiments among undergraduate nursing students utilizing mobile technology as learning intervention tools in their nursing studies were included. If the abstract was found to be relevant, the full publication was reviewed. Table I show a total of 12 eligible articles that were finally selected into review of this study. 


\section{FINDINGS OF THE REVIEW}

\section{A. Study Details and Research Designs}

There are twelve studies originated from four different countries, most of the studies were conducted in recent three years (seven out of twelve) which indicate to us that there is increasing interest to know more about the effectiveness of mobile technology as a tool for learning in nursing education. The studies were mostly conducted in South Korea (8 studies) followed by Taiwan (2 studies) and one study in both Finland and Brazil.

Most of these identified studies had conducted randomized experimental or quasi-experimental design. Seven out of twelve reported the employment of quasi-experimental pre-posttest, meanwhile four used randomized-controlled trial, and one experimental pre-posttest. However in terms of sampling size, there is variation among these studies with the smallest size of the sample is 22 participants [23] and the largest is 157 participants [28].

Table II Features of mobile interventions, comparison groups and results of the study

\begin{tabular}{|c|c|c|}
\hline Study & $\begin{array}{l}\text { Features of mobile } \\
\text { intervention }\end{array}$ & Comparison group \\
\hline [20] & $\begin{array}{l}\text { - Use of VLO for simulation } \\
\text { - Tutorial, Feedback, Help } \\
\text { link }\end{array}$ & $\begin{array}{l}\text { - Virtual Learning } \\
\text { Object } \\
\text { - No control }\end{array}$ \\
\hline [21] & $\begin{array}{l}\text { - Voice narration in the } \\
\text { demonstration video } \\
\text { - Online streaming rather } \\
\text { than downloading } \\
\text { - Recording frequency of } \\
\text { video play }\end{array}$ & $\begin{array}{l}\text { - Mobile-based video } \\
\text { - No intervention }\end{array}$ \\
\hline [22] & $\begin{array}{l}\text { - Use instructional content } \\
\text { and voice narration during } \\
\text { video demonstration. }\end{array}$ & $\begin{array}{l}\text { - Smartphone } \\
\text { application } \\
\text { - No intervention }\end{array}$ \\
\hline
\end{tabular}

Results

- Post-test $(7.51 \pm 1.98)$ showed a significant increase in student learning compared to the results of the pre-test ( $p$ $<0.0001)$.

- There was no significant difference between the groups for skill performance in urinary catheterization $(\mathrm{t}=1.194, \mathrm{p}=$ 0.236).

- There was no significant difference between the groups in learning motivation $(\mathrm{r}=0.515, \mathrm{P}=.001)$

- There was no significant difference between the groups in class satisfaction $(\mathrm{r}=0.548, \mathrm{P}=.001)$

- There was no statistically significant difference between smartphone application group and control group in knowledge $(\mathrm{t}=0.886, \mathrm{p}=0.379)$.

- There were statistically significant difference in skills $(\mathrm{t}=$ $4.774, \mathrm{p}<0.001)$ and confidence in performance $(\mathrm{t}=$ $2.888, \mathrm{p}=0.005)$

- There was no statistically significant difference between the two groups in satisfaction $(\mathrm{t}=.168, \mathrm{p}=0.867)$

[23] - Sharing, exchange, and - Tablet PC with PBL interaction among peers, - PBL only teachers, and students $\quad$ No intervention

- Receive guidance and feedback

[24] - Providing heart and lung • Mobile application sound

- High fidelity simulator

- There was a statistically significant difference among the three groups in knowledge $(\mathrm{p}=.000<.05)$.

- There was no statistically significant difference between the two groups in cognitive $(\mathrm{P}=.142>.05)$

- There was a statistically significant difference among the groups in knowledge $(\mathrm{p}=0.031)$.

- There was no statistically significant difference between the two groups in practice clinical assessment skills with respect to lung assessment $(\mathrm{p}=0.258)$ and heart assessment $(\mathrm{p}=0.258)$.

[25] - Discussion communication

- Receive feedback

[26] - Document function

- Auto calculation

- Data linked to student's email

- Patient assessment tools and - Mobile application

- Computer web-based discussion group

- Mobile application

- No intervention
- There was a statistically significant difference between groups in extrinsic motivation $(\mathrm{p}=0.011)$

- There was no statistically significant difference between the two groups in satisfaction $(\mathrm{t}=1.525, \mathrm{p}=0.134)$

- There was no statistically significant difference between the two groups in critical thinking $(t=1.920, p=0.060)$ 
[27] • Video recording only

[28] - Practical game: Score and ranking

[29]

- Video recording

- Expert comment

- Video of demonstration

- Smartphone video +

- Receive 'reminder' to DVD view the video

- DVD only

[31]

- Schedule of practicum

- Mobile application

- Social networking-style • No intervention element group, for teacher-learner interaction

- Teacher able to control documentation and offer feedback and support

\section{B. Comparative Interventions}

A variety of mobile technologies were used in this study such as mobile application, smartphone-based video, and mobile web. Seven from the studies has incorporated the use of video in their intervention. Seven studies were using mobile-based intervention as compared to conventional or standard intervention such as lectures and procedure demonstrations. Meanwhile, there were three studies compared mobile-based intervention group with other types of interventions such as PBL, DVD and simulator.

\section{Accessibility and Portability}

Mobile-based learning has been recognized as an essential way to enhance learning among nursing students in all settings such as classroom [20], [22], [23], [32], simulated skill laboratory [21], [22], [24] and clinical site [26], [31]. These studies have discussed various functions used in this technology such as video, mobile app, and social media. Henceforth, it aided us to understand the reality in using mobile technology in different nursing education context
- There was a statistically significant difference between groups in extrinsic practice competency $(\mathrm{p}=0.019)$

- There was no statistically significant difference between the two groups in satisfaction with practice $(\mathrm{p}=0.152)$ and satisfaction with practice method $(\mathrm{p}=0.879)$

- There was a statistically significant difference between groups in self-efficacy $(\mathrm{p}=0.019)$

- There was a statistically significant difference between groups among the above-mean group in extrinsic practice competency learning achievement $(\mathrm{Z}=3.16, \mathrm{p}=.002)$

- There was a statistically significant difference between groups above-mean group in total metacognition $(\mathrm{Z}=2.50$ $\mathrm{p}=.012$ )

- All outcomes variables in the experimental group were lower than in the control group for 'below-mean group'

- There was no statistically significant difference between the two groups in satisfaction $(\mathrm{t}=1.160, \mathrm{p}=.250)$.

- There was no statistically significant difference between the two groups in nursing skill ( $\mathrm{t}=.403, \mathrm{p}=.688)$.

- There was a statistically significant difference between the two groups in self-efficacy $(\mathrm{t}=3.093, \mathrm{p}=.003)$.

- There was a statistically significant difference between the two groups in knowledge $(\mathrm{F}=4.219, \mathrm{p}=0.04)$

- There was a statistically significant difference between the two groups in skill $(\mathrm{F}=6.739, \mathrm{p}=0.013)$

- There was no statistically significant difference between the two groups in confidence level $(\mathrm{F}=2.201, \mathrm{p}=0.142)$

- There was no statistically significant difference between the two groups in competence $(\mathrm{p}=0.57)$

- There was no statistically significant difference between the two groups in satisfaction on clinical learning environment $(\mathrm{p}=0.24)$

- There was no statistically significant difference between the two groups in self-efficacy on clinical learning environment $(p=0.37)$

such as health assessment, health education, skill performance, and learning motivation.

Most of the studies in this review found nursing students expressed likeliness of the portability and accessibility to the rich content and information that mobile device offer. It is irrefutable mobile device is more accessible as compared to other technology-enhanced learning tools such as computer [25]. It gives more advantages due to its function such as supporting internet connection and designed to be served as a dynamic and interactive tool [20]. Students are also owing to the benefit that it can be accessed anytime and anywhere especially in clinical context. Moreover, Kim et al. [22] believed smartphone-based education had provided them with easy accessible environment for self-review of their learning.

\section{Outcomes Measures}

In the synthesis of the effectiveness of mobile technology in nursing education, outcome measures were impressed through its results. Table II above shows the summary of the skill competency,

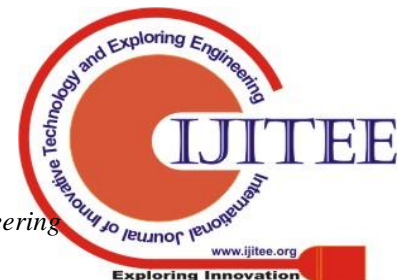


knowledge score, confidence and satisfaction level which is varied across the studies. Evaluation of skill performance by assessors using a structured checklist tool or institutional protocol was reported in several papers [21], [22], [24], [29], [30]. Knowledge tests were featured in the studies commonly involved the use of self-developed questions [20], multiple-choice questions and true-false questions and quizzes [22], [30]. Meanwhile, to determine confidence score, instruments used included five items C-scale [30], action-based score [22], and survey such as Instructional Materials Motivation Survey [21].

\section{E. Effect of Mobile-Based Learning on Skill Performance}

There are six studies tested out students' skill performance, and half of interventions [21], [24], [29] have shown no significant difference between intervention and control groups. However, there was a statistically significant difference found in the remaining three of the studies [22], [27], [30].

For instance, Kim et al. [22] reported statistically higher post-test scores related to measuring performance when providing care for infant airway obstruction between intervention group using smartphone video demonstration with conventional intervention. Likewise, there is a significant difference post-test result $(\mathrm{p}=0.019)$ between the group of using smartphone video recording with the control group in intramuscular injection practice [27]. Meanwhile, Chuang et al. [30] found that learning with additional smartphone video after demonstration of urinary catheterization is significant as compared to control group whom utilizing DVD only.

However, in terms of skill performance outcomes, there were no statistically significant changes in students who were utilizing mobile-based learning as compared to the group who using conventional method. In fact, lower skill score were reported among students in intervention groups using mobile-based video in practising urinary catheterization [21], mobile app in assessment of lung and heart [24], and social network-based video in tracheostomy care [29].

\section{F. Impact of Mobile-Based Learning on Cognitive Recall}

Results from reported studies were mixed based on the effect of mobile-based learning on cognitive recall. Higher knowledge scores on this group were reported in three studies [23], [24], [30]; however only one [22] was found to be not significant in retention of knowledge after the intervention. Meanwhile, for Alvarez et al. [20], post-test score is significant $(\mathrm{p}<0.0001)$ as compared to its pre-test after using virtual learning object in the intervention of assessment of acute pain.

\section{G. Impact on Self-efficacy and Satisfaction}

Learner's self-efficacy with mobile technology in learning was positive in three studies [21], [25], [29], but it was not significant in the study conducted by Strandell-Laine et al. [31]. High level of learner satisfaction with mobile technology in learning were reported in two studies [22], [27]. However, the learner satisfaction were found did not significant between intervention and control group in studies with a poor result of skill practice intervention [24], [29].

\section{H. Mobile Learning Features}

Further, mobile technology has been famous for improving students' learning and performance. Video approach is the most intervention method used in the studies. Lee et al. [21] inferred no changes in intervention after the students were given one week to use mobile-based video for learning urinary catheterization procedure. Since the type of procedure given was for a high level of complexity, more time must be given to help the students to attain the better result.

However, the feedback features have helped the students to see how well they are performed through receiving responses from their peers. Besides, Kim et al. [22] have shown the fragmented result on knowledge and skill on intervention group of students using video with additional instructional content and narration in managing airway obstruction of infants. Further, the absence of active learning such as feedback in this study has caused cognitive retention of knowledge and satisfaction deteriorated. Chuang et al. [30] have confirmed that the use of video demonstration in correspond with feedback elements from other people such as educator, yielded effective intervention result in skill and knowledge retention. There was no significant difference in skill, satisfaction and self-efficacy on the effectiveness of social network-based video in learning, as reported by Jeong and Kwon [29]. Although the study has instituted expert involvement in giving feedback on learning, improvement can be seen only within the intervention group.

Other than video-based approach, the other mobile technologies features used by the students are virtual learning object (VLO), auditory element and communication. An intervention study by Alvarez et al. [20], VLO has helped them in the contextualization of knowledge and has encouraged problem-solving. However, there was still an ambiguity in this study whereby two students had decreased performance in the post-test and another three students reported minimal improvement. Then, Yoo and Lee [24] highlighted the learning impact of using auditory element in a mobile application is similarly effective with learning using the high-fidelity simulator in improving knowledge retention, but not in skill practice and satisfaction. It was suggested combining both approaches, mobile and conventional, is needed to attain more fruitful results. Knowledge and skill were enhanced with the presence of feedback function and interaction in using mobile assistance learning system during PBL [23]. In this study, the students received feedback immediately, further, helped to solve the problem they encounter. Strandell-Laine et al. [31] who have examined the level of cooperation during students' practicum has shown that there was a significant association with the improvement in managing learning situations. Mobile 
technology helped the students to document their learning activities and communicate effectively throughout their practicum period.

To sum up, the improvement of skill among the intervention group was highlighted due to the opportunity to review the learning content repeatedly. The students had the chance to study on their own pace and self-study [20], [21], [32] resulted to stimulated independent and autonomy in the learning process, improvement of confidence, satisfaction, and motivation. Satisfaction of using video as a learning method is improved due to the flexibility, and students can manage to see how they perform through feedback received. $\mathrm{Wu}$ [23] found that technology has offered students with a reflection of their study have helped them to develop critical thinking and to promote the acquisition of knowledge. Meanwhile, mobile technology use has encouraged reflection of learning while also respecting their individuality [20]. Opportunity to consult the educators also has contributed to receiving feedback and self-review on own performance. Besides, self-assessment and peer-assessment were manoeuvring students to learn to accept multiple perspectives. This hence stimulates more desires for learning among students.

\section{DISCUSSION}

This review highlighted how mobile technologies had been scrutinized in benefit of nursing education and to ascertain how mobile features have been exploited in engaging learners with the content of learning. The review has collectively addressed positive learning outcomes in comparison to traditional methods for example increased learner accessibility to information, perceived improvement in knowledge and skill and improved satisfaction of learning. Based on the findings obtained in this review, it can be naturally narrated students who were being actively engaged in their learning is seen as a novel and motivating form of independently acquiring knowledge. In respect to self-directed learning, mobile learning assists the learner to learn informally and independently [33].

Although some group of students may feel learning using a smartphone is useful; however there is still a need for consideration for groups who are not familiar with the use of technology. It is essential to keep all groups of students in view for continuous engagement with the mobile-assisted learning. Based on the evidence from Wang, Wu and Wang [34], the use of m-learning has managed to give a significant result of usefulness and ease of use among older learners since they have lower computer self-efficacy.

Besides, even though the students were well interacting with mobile learning, however it is important to bear in mind that it has few limitations to be considered. In spite of mobile learning offers motivation for learning, barriers of the usage have to be understood particularly at the earlier stage of mobile learning development. Hence, any considerations on the user context of the acceptance and use of the technology can be made to foresee possible outcomes. For example, Donaldson [35] was determined to examine if Unified
Theory of Acceptance and Use of Technology (UTAUT) and additional constructs are factors in community college students' intention to use and actual use of mobile learning.

There are also few studies showing fragmented results in knowledge and skills in performing a procedure in which either skill or knowledge show improvement or the tool may only effective for certain types of clinical procedures only. In this sense, mobile-based enhanced learning may not be suited to all topics or learning style. Moreover, to reflect the lack of effectiveness on learning, for instance during performing urinary catheterization on male [21], the mobile-based tool may be useful for knowledge and skill acquisition in the area of less complicated procedures. For students who can perform well in skill but not in knowledge acquisition, they may need a longer time to grasp all the necessary knowledge and rationale. Lee et al. [21] have stated that one week may not be enough to learn about a complicated procedure using mobile-based video. A prior study conducted by Holland et al. [36], using online video to learn a less complex procedure such as oral medication administration, alone need 15 weeks to record a lower number of failures. In short, by emphasizing the users' tasks, needs and goals at the early learning tool design, better results can be achieved for example instilling the element which can improve the frequency of viewing and engagement of video playing time.

There are studies presented issues related to the study method. Pre- post-test studies without any comparison group may raise the concern of actual tool effectiveness due to confounding influences that can affect the scores, for instance, prior knowledge and skill experience. By acknowledging the level of prior knowledge and experience between low performer and high performer through initial assessment, we can achieve better result during an intervention. Kenny et al. [37] suggested there may be a need to provide some differentiated instruction on the mobile-based product to be used in class based on the level of experience on computing. According to Mao and Palvia [38], as IT users become more experienced, their perceived internal influences and external influences are more consistent with the use of technology.

Besides, the use of a quantitative approach only to measure the satisfaction rate of the mobile device in learning seemed to be inadequate. A better approach such as mixed method which combines pre and post-test design with qualitative exploration can be more encouraging in this type of study. In-depth information can be explored at the same time any information that needs confirmation can be asked directly. Therefore, mixed method will be more appropriate to capture many elements of learning such as perception, knowledge, and satisfaction. Mixed method approach combining both qualitative and quantitative technique is not a new concept in information system field, most importantly it offers the potential to foster theory building [39]. Donaldson [35], for example, used a mixed method to examine the determinants associated with community college students' behavioral intention to use of mobile learning and mobile library resources. 
When treating different groups of subjects for intervention study, ethical issue must be taken into consideration. It must be appropriate while allocating the intervention subject by controlling the useful resource from the control group. Preventing data contamination across groups is important. For example, Lee et al. [21] found data contamination was their limitation when conducting Randomized Controlled Trial study that both experimental and control group were sharing the same laboratory for practice.

\section{CONCLUSION}

In summary, this review found that most of the studies highlighted the effectiveness of using mobile-based learning and features associated with it. More than half of studies conducted using video as a medium of learning, but the outcomes were unclear. The results were depending on the types of learning outcomes, few studies were found to be effective in retention of knowledge, but few were not in skill acquisition. Interestingly, most of the shared interests were discussed mainly give a contribution towards motivating factors and barriers on acceptance of the mobile technology in nursing education, for example, the usefulness, efficiency, social interaction and organizational support. There are students who expressed significant positive notions regarding the adoption of mobile in their self-directed learning. Therefore, this is ideally suited for undergraduate nursing students who are often faced with limited time and constrained freedom to engage in direct face to face clinical skill.

From the findings of the review, the following recommendations for mobile-based interventions on nursing education have emerged:

1) Given the benefits of mobile-enhanced learning, this should be considered in undergraduates nursing curriculum. More activities in classroom and clinical skill laboratory with mobile supported tools should be incorporated as complementary with face-to-face teaching and learning.

2) More reflection-based activities should be incorporated within the mobile app features for learning such as peer and educator-assessment and forum to enhance interaction among learners while receiving multiple opinions or perspectives.

3) The design and development of learning tool must be incorporated the needs of every stakeholder involved within the environment such as students, teacher, faculty management and the sponsor start from the beginning.

4) Behavior is a significant determinant for someone to utilize an innovative tool for learning. Hence, the acceptance criteria of the target population using such technology must be incorporated as a backbone for mobile intervention development.

\section{ACKNOWLEDGMENT}

The author would like to thank to International Islamic University of Malaysia for funding the project under Research Initiative Grant Scheme (RIGS).

\section{REFERENCES}

[1] V. R. Terry, C. Moloney, L. Bowtell, and P. C. Terry, "Online intravenous pump emulator: As effective as face-to-face simulation for training nursing students," Nurse Educ. Today, vol. 40, pp. 198-203, 2016.

[2] S. Baraz, R. Memarian, and Z. Vanaki, "Learning challenges of nursing students in clinical environments: A qualitative study in Iran," vol. 4, no. August, pp. 1-9, 2015.

[3] M. S. Yoo, Y. J. Son, Y. S. Kim, and J. H. Park, "Video-based self-assessment: Implementation and evaluation in an undergraduate nursing course," Nurse Educ. Today, vol. 29, no. 6, pp. 585-589, 2009.

[4] S. Eisner, "Managing Generation Y," S.A.M. Adv. Manag. J., vol. 70, no. 4, 2005.

[5] C. Chang, C. Lai, and G. Hwang, "Trends and research issues of mobile learning studies in nursing education: A review of academic publications from 1971 to 2016," Comput. Educ., vol. 116, pp. 28-48, 2018.

[6] J. Raman, "Mobile technology in nursing education: WHERE do we go from here? A review of the literature," Nurse Educ. Today, vol. 35, no. 5, pp. 663-672, 2015.

[7] C. Strandell-laine, M. Stolt, H. Leino-kilpi, and M. Saarikoski, "Use of mobile devices in nursing student - nurse teacher cooperation during the clinical practicum: An integrative review," Nurse Educ. Today, 2014.

[8] G. J. Doyle, B. Garrett, and L. M. Currie, "Integrating mobile devices into nursing curricula: Opportunities for implementation using Rogers ' Diffusion of Innovation model," Nurse Educ. Today, vol. 34, no. 5, pp. 775-782, 2014.

[9] J. C. Phillippi and T. H. Wyatt, "Smartphones in Nursing Education," Comput. Informatics Nurs., vol. 29, no. 8, p. 449-454 10.1097/NCN.0b013e3181fc411f, 2011.

[10] T. P. George, C. DeCristofaro, P. F. Murphy, and A. Sims, "Student Perceptions and Acceptance of Mobile Technology in an Undergraduate Nursing Program.," Healthcare, vol. 5, no. 3, p. $35,2017$.

[11] S. O'Connor and T. Andrews, "Mobile Technology and Its Use in Clinical Nursing Education: A Literature Review," J. Nurs. Educ., vol. 54, no. 3, pp. 137-144, 2015.

[12] P. Beauregard, A. Arnaert, and N. Ponzoni, "Nursing students' perceptions of using smartphones in the community practicum: A qualitative study," Nurse Educ. Today, 2017.

[13] B. Hay et al., "“ iM Ready to Learn ': Undergraduate Nursing Students' Knowledge, Preferences, and Practice of Mobile Technology and Social Media," Comput. Informatics, Nurs., no. January, pp. 8-17, 2017.

[14] N. Airth-kindree and R. T. Vandenbark, "Mobile Applications in Nursing Education and Practice," Nurse Educ., vol. 39, no. 4, pp. 166-169, 2014.

[15] A. S. M. Mosa, I. Yoo, and L. Sheets, "A systematic review of healthcare applications for smartphones," BMC Med. Inform. Decis. Mak., vol. 12, no. 67, 2012.

[16] S. Gokcearslan, "Perspectives of Students on Acceptance of Tablets and Self- directed Learning with Technology," Contemp. Educ. Technol., vol. 8, no. 1, pp. 40-55, 2017.

[17] H.-J. Jung, "Ubiquitous Learning: Determinants Impacting Learners' Satisfaction and Performance With Smartphones," Lang. Learn. Technol., vol. 18, no. 3, pp. 97-119, 2014.

[18] L. Sha, C. K. Looi, W. Chen, P. Seow, and L. H. Wong, "Recognizing and measuring self-regulated learning in a mobile learning environment," Comput. Human Behav., 2012.

[19] H. Lee, H. Min, S. M. Oh, and K. Shim, "Mobile technology in undergraduate nursing education: A systematic review," Healthc. Inform. Res., vol. 24, no. 2, pp. 97-108, 2018.

[20] A. G. Alvarez, G. T. M. Dal Sasso, and M. S. Iyengar, "Persuasive technology in teaching acute pain assessment in nursing: Results in learning based on pre and post-testing," Nurse Educ. Today, vol. 50, pp. 109-114, 2016.

[21] N. Lee, S. Chae, H. Kim, J. Lee, H. J. Min, and D. Park, "Mobile based video learning in clinical nursing: A Randomized Controlled Trial," Comput. Informatics, Nurs., vol. 34, no. 1, pp. 8-16, 2016.

[22] S. Kim, H. Shin, J. Lee, S. Kang, and R. Bartlett, "A smartphone application to educate undergraduate nursing students about providing care for infant airway obstruction," Nurse Educ. Today, vol. 48, pp. 145-152, 2017.

[23] T. Wu, "The Use of a Mobile Assistant Learning System for Health Education Based on 
Project-Based Learning," Comput. Informatics, Nurs., vol. 32, no. 10, pp. 497-503, 2014.

[24] I.-Y. Yoo and Y.-M. Lee, "The effects of mobile applications in cardiopulmonary assessment education," Nurse Educ. Today, vol. 35, no. 2, pp. e19-e23, 2015.

[25] M. K. Lee, "Effects of mobile phone-based app learning compared to computer-based web learning on nursing students: Pilot randomized controlled trial," Healthc. Inform. Res., vol. 21, no. 2, pp. 125-133, 2015.

[26] M. Choi, H. S. Lee, and J. H. Park, "Effects of using mobile device-based academic electronic medical records for clinical practicum by undergraduate nursing students: A quasi-experimental study," Nurse Educ. Today, vol. 61, pp. $112-119,2018$

[27] H. S. Jeong, "Effects of nursing students' practices using smartphone videos on fundamental nursing skills, self-efficacy, and learning satisfaction in South Korea," Eurasia J. Math. Sci. Technol. Educ., vol. 13, no. 6, pp. 2351-2365, 2017.

[28] K. Y. Park and M. S. Kim, "Outcomes of a drug dosage calculation training smartphone app on learning achievement, metacognition, and flow state according to prior knowledge," Eurasia J. Math. Sci. Technol. Educ., vol. 14, no. 7, pp. 2867-2876, 2018.

[29] H. Jeong and H. Kwon, "Effect of Learning Core Fundamental Nursing Skill with Social Network Service (SNS) for Nursing Students in South Korea," Eurasia J. Math. Sci. Technol. Educ., vol. 14 , no. 10 , pp. $1-10,2018$

[30] Y. H. Chuang, F. C. Lai, C. C. Chang, and H. T. Wan, "Effects of a skill demonstration video delivered by smartphone on facilitating nursing students' skill competencies and self-confidence: A randomized controlled trial study," Nurse Educ. Today, vol. 66, pp. 63-68, 2018.

[31] C. Strandell-Laine, M. Saarikoski, E. Löyttyniemi, R. Meretoja, L. Salminen, and H. Leino-Kilpi, "Effectiveness of mobile cooperation intervention on students' clinical learning outcomes: A randomized controlled trial," J. Adv. Nurs., vol. 74, no. 6, pp. 1319-1331, 2018.

[32] M. Davies, "Using the Apple iPad to facilitate student-led group work and seminar presentation," Nurse Educ. Pract., pp. 1-5, 2014.

[33] S. Karimi, "Do learners ' characteristics matter? An exploration of mobile-learning adoption in self-directed learning," Comput. Human Behav., vol. 63, pp. 769-776, 2016.

[34] Y. Wang, M. Wu, and H. Wang, "Differences in the acceptance of mobile learning," Br. J. Educ. Technol., vol. 40, no. 1, pp. 92-118, 2009.

[35] R. Donaldson, "Student acceptance of mobile learning," Procedia Soc. Behav. Sci., vol. 8, no. 2, pp. 2477-2481, 2011.

[36] A. Holland, F. Smith, G. Mccrossan, E. Adamson, S. Watt, and K. Penny, "Online video in clinical skills education of oral medication administration for undergraduate student nurses: A mixed methods , prospective cohort study," Nurse Educ. Today, vol. 33, no. 6, pp. 663-670, 2013.

[37] R. F. Kenny, J. M. C. Van Neste-Kenny, P. A. Burton, and J. Meiers, "Using Mobile Learning to Enhance the Quality of Nursing Practice Education," in Mobile learning: Transforming the Delivery of Education and Training., Canada: Athabasca University Press, 2009, pp. 75-98.

[38] E. Mao and P. Palvia, "Exploring the effects of direct experience on IT use An organizational field study," Inf. Manag., vol. 45, no. 4, pp. 249-256, 2008

[39] P. F. Wu, "A Mixed Methods Approach to Technology Acceptance Research,” J. Assoc. Inf. Syst., vol. 13, no. 3, pp. 172-187, 2012.

\section{AUTHORS PROFILE}

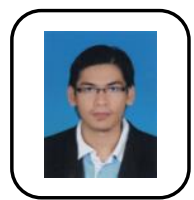

Airul Azizan Zainudin is currently an academic trainee and $\mathrm{PhD}$ student at Kulliyyah of Nursing, International Islamic University of Malaysia. He obtained his Bachelor of Nursing from International Islamic University of Malaysia in 2011. He worked as a registered nurse in a renal care center before joining a healthcare IT solutions company. He worked side-to-side with IT programmer and medical practitioners in designing, testing, commissioning and training in healthcare management products and services. In 2016, he received Master of Informatics from Universiti Sains Malaysia. His scientific interest is in the area of nursing informatics and nursing education. airul@iium.edu.my

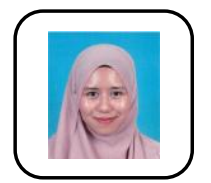

Hazwani Mohd Mohadis is currently a lecturer at the Department of Information System, Kulliyyah of ICT, International Islamic University of Malaysia. She obtained her BSc. (Hons.) Netcentric Computing from Universiti Teknologi MARA in 2010, MSc. in Human Computer Interaction and Ergonomics from University College London in 2013 and $\mathrm{PhD}$ in Visual Informatics from Universiti Kebangsaan Malaysia in 2017. Her main interest is in the area of human computer interaction, interaction design, user-centered design, user experience, persuasive system design and behaviour change support system.

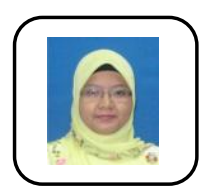

Norfadzilah Ahmad is currently a lecturer and head of department of the Department of Department of Professional Nursing Studies, Kulliyyah of Nursing, International Islamic University of Malaysia. She received her BSc. (Hons.) Nursing from Universiti Malaysia Sarawak and MSc. Medical Education from Universiti Sains Malaysia and $\mathrm{PhD}$ degree in Nursing and Midwifery from Queen's University of Belfast. She is a member of Malaysia Nursing Association (MNA) and Malaysia Society for Simulation in Healthcare (MASSH). 